\title{
Examination of benefits sought by hiking tourists: a comparison of impact-range performance analysis and impact asymmetry analysis
}

Munhyang (Moon) Oh, Seongseop (Sam) Kim, Youngjoon Choi \& Stephen Pratt

To cite this article: Munhyang (Moon) Oh, Seongseop (Sam) Kim, Youngjoon Choi \& Stephen Pratt (2019) Examination of benefits sought by hiking tourists: a comparison of impact-range performance analysis and impact asymmetry analysis, Asia Pacific Journal of Tourism Research, 24:8, 850-864, DOI: 10.1080/10941665.2019.1635501

To link to this article: https://doi.org/10.1080/10941665.2019.1635501

Published online: 07 Jul 2019.

Submit your article to this journal ¿

View Crossmark data ¿ 


\title{
Examination of benefits sought by hiking tourists: a comparison of impact-range performance analysis and impact asymmetry analysis
}

\author{
Munhyang (Moon) Oh${ }^{\mathrm{a}}$, Seongseop (Sam) Kim (D) ${ }^{\mathrm{a}}$, Youngjoon Choi ${ }^{\mathrm{a}}$ and Stephen Pratt (D)

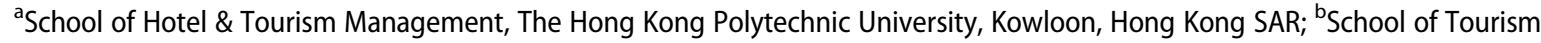 \\ and Hospitality Management, University of the South Pacific, Fiji, Australia
}

\begin{abstract}
This study assesses the benefits of hiking for visitors to the Jeju Olle Trail on Jeju Island in Korea, which has been designated as a World Heritage Site. Data were collected from a total of 318 tourists visiting the Jeju Olle Trail. The study focused on comparing the benefits sought by first-time visitors and those of repeat visitors. Analytical results found that first-time visitors and repeat visitors sought different benefits from their hiking experiences. First-time visitors sought to observe nature and interact with people. For first-time visitors, benefits that delighted them were buying unique souvenirs and enjoying educational experiences, whereas repeat visitors demonstrated a good assessment on interactions with new people and buying unique souvenirs.
\end{abstract}

\section{KEYWORDS}

Benefits; hiking; impactrange performance analysis (IRPA); impact asymmetry analysis (IAA); satisfaction; Jeju; island; first-time; repeat; sustainable; trekking

\section{Introduction}

Adverse impacts of mass tourism have led to alternative new tourism patterns that require social and environmental responsibility from all stakeholders, including the tourists themselves, corporate entities, policy makers, and local residents (Adongo, Kim, \& Elliot, 2019; Prince \& loannides, 2017; Su, Swanson, \& Chen, 2018; Weaver, 2001). Many of the approaches to alternative forms of tourism seek to synchronize tourism with the preservation of local culture and nature (Adongo \& Kim, 2018; Honey, 2008; Weaver \& Lawton, 2007). Ecotourism has emerged from those efforts and encompasses a variety of terms, such as nature-based tourism, adventure tourism, alternative tourism, and green tourism (Honey, 2008; Prince \& loannides, 2017).

Among those diverse dimensions, hiking is one tourist activity that is evoked as an intersection concept, combining ecotourism, cultural tourism, and adventure tourism (Gyimóthy \& Mykletun, 2004; Mu \& Nepal, 2016; Weaver, 2001). As a core tourism product, hiking tourism includes a wide range of conditions that are attractive tourism products, such as sensory pleasures, aesthetics, education, health, adventure, relaxation, and spirituality (Kastenholz \& Rodrigues, 2007). From the viewpoint of the local government of a tourist destination, hiking trail development is imperative because it helps to expand the destination's variety of tourist attractions and promotes its authentic culture and natural scenic magnificence (Moore \& Shafer, 2001; Wolf, Brown, \& Wohlfart, 2017).

Approximately $13 \%$ of Americans participated in hiking activities in 2016 - a significant increase from 9.2\% in 2012 (Statista, 2017). In South Korea, the popularity of hiking has continued since 2007, when the first hiking trail on Jeju Island, the Jeju Olle Trail (JOT), was launched. The popularity of that trail has increased along with the growth of slow tourism values and has inspired the development of roughly 595 hiking trails all over the country, with various themes such as mountain trails, pine tree forest trails, Confucianism cultural trails, ecology and culture trails, and forest therapy trails (Kang, 2014; Lee, Kim, Graefe, \& Chi, 2013; Woo, Sohn, San Ahn, Yoon, \& Spate, 2013). The JOT has had a huge

CONTACT Seongseop (Sam) Kim sam.kim@polyu.edu.hk School of Hotel \& Tourism Management, The Hong Kong Polytechnic University, 17 Science Museum Rd., TST East, Kowloon, Hong Kong SAR 
influence on various aspects of the community, such as enhancement of community unity, health, and well-being, and formulation of a new community business environment in the trail communities (Lee et al., 2013; Woo et al., 2013).

Although the above-noted literature has highlighted an increasing research interest in hiking tourism, important research gaps exist. First, most hiking studies have focused on analyzing the dimensions of benefits sought from hiking (Nordbø \& Prebensen, 2015; Wolf et al., 2017; Wolf \& Wohlfart, 2014). Some studies have been limited to assessing hiking trail features and benefits (Kastenholz \& Rodrigues, 2007; Sarigöllü \& Huang, 2005). In particular, some studies have analyzed the role of subjective benefits of well-being, in association with hikers' motivation or values (Kim, Lee, Uysal, Kim, \& Ahn, 2015; Wolf \& Wohlfart, 2014). Nevertheless, previous studies have failed to explore in detail which of the various benefits really delight hikers, and why.

Second, previous studies have identified the importance of understanding the dissimilarity between firsttime visitors and repeat visitors. Those studies' findings have indicated that the travel experiences, perceptions, and behaviors of the two groups of visitors differ (Petrick, 2004; Um, Chon, \& Ro, 2006). For instance, first-time visitors focus more on information about a destination's attributes, and their perception of quality is lower than that of repeat visitors. They are attracted to new attractions in a destination, and it costs more to promote to them. Repeat visitors focus more on a destination's emotional or psychological significance, so recalling their positive memories can attract them with less expense. In light of that, hikers who are visiting hiking trails probably have different needs, but few studies so far have explored those differences.

Third, few studies have used two new methods, IRPA and IAA to assess hikers' experiential quality (Nordbø \& Prebensen, 2015). These methods go beyond importance-performance analysis (IPA) which is vulnerable to flaws, such as the vagueness of the concept of importance, a lack of convergent validity because of the different interpretations of the importance attributed to different measurements, and the arbitrariness of the selection of cutoff points between scale means and grand means of performance and importance scores (Jaccard, Brinberg, \& Ackerman, 1986; Mikulić \& Prebežac, 2008).

Because of the existing research gaps and the need to provide practical hiking recommendations, it is important to compare the underlying needs of firsttime visitors to the Jeju Olle hiking trail with the needs of repeat visitors. This study has four specific objectives. First, it compares profiles of sociodemographic and travel-related characteristics of first-time visitors with those of repeat visitors. Second, the performance of each benefit of the JOT is compared with the impact on hiker satisfaction, by using IRPA. Third, impact asymmetry is calculated and interpreted, according to the steps of IAA, in order to recognize the role that each benefit has on the hikers' delight in their hiking experience. By using two methods that can identify the fundamental needs and excitement factors of the JOT experience for first-time and repeat-visit hikers, this study aims to bridge the gaps in previous research and also offers managerial insights.

\section{Literature review}

\section{Benefits associated with hiking tourism}

Studies of hiking benefits have addressed the fact that hiking offers a variety of benefits, including improved physical and mental health, nature appreciation, learning, socialization, and adventure seeking. First, most studies present a consensus that hiking benefits people's physical and mental health (Freidt, Hill, Gómez, \& Goldenberg, 2010; Keniger, Gaston, Irvine, \& Fuller, 2013; Kim, Kim, \& King, 2016; Li, Bin, \& Ryan, 2017; Maria Raya, Martínez-Garcia, \& Celma, 2017).

Hikers also can experience a second suite of benefits: the opportunity to appreciate scenery, be engrossed in nature, enjoy fresh air, watch wildlife, and learn. A third type of benefit to hikers is educational and cultural: learning about an area's nature, including the local wildlife, environment, and geography, and about the local culture, customs, and history. Those benefits are closely associated with the discovery of new knowledge or with satisfying a noveltyseeking desire, through visiting a museum or heritage site, visiting an ethnic group village, or observing wildlife (Barton, Hine, \& Pretty, 2009; Collins-Kreiner \& Kliot, 2016; Kastenholz \& Rodrigues, 2007; Kim et al., 2015; Marafa, Ting, \& Cheong, 2007; Wolf \& Wohlfart, 2014).

A fourth type of benefit is that of socialization. Hiking tourism can be enjoyed alone or with family, friends, and like-minded people. Hiking offers a good opportunity to strengthen family/ friend bonds, pursue intimacy, and meet people with one's same interests. Further, active adventure seekers attempt to enjoy adventure by 
Table 1. Hiking benefits highlighted in literature.

\begin{tabular}{|c|c|c|}
\hline A priori domains & Items & Previous studies \\
\hline Nature-based/eco-tourism & $\begin{array}{l}\text { - Enjoying nature/viewing the scenic beauty } \\
\text { - Experiencing nature } \\
\text { - Enjoying the fresh air } \\
\text { - Looking at scenery } \\
\text { - Watching wildlife } \\
\text { - Feeling a love of nature }\end{array}$ & $\begin{array}{l}\text { Barton et al. (2009); Collins-Kreiner and Kliot } \\
\text { (2016); Kastenholz and Rodrigues (2007); Kim } \\
\text { et al. (2015); Marafa et al. (2007); Wolf and } \\
\text { Wohlfart (2014) }\end{array}$ \\
\hline Active adventure tourism & $\begin{array}{l}\text { - Physically exercising } \\
\text { - } \text { Being active outdoors } \\
\text { - Keeping/getting fit } \\
\text { - Pursuing physical and athletic goals } \\
\text { - Pursuing serious leisure } \\
\text { - Taking exercise } \\
\text { - Pursuing a healthy lifestyle }\end{array}$ & $\begin{array}{l}\text { Barton et al. (2009); Kastenholz and Rodrigues } \\
\text { (2007); Kim et al. (2015); Marafa et al. (2007); } \\
\text { Nordbø and Prebensen (2015); Wolf and } \\
\text { Wohlfart (2014) }\end{array}$ \\
\hline Educational/cultural tourism & $\begin{array}{l}\text { - Learning more about the nature and culture } \\
\text { - Pursuing spiritual and cultural motivation } \\
\text { - Pursuing religious motivation } \\
\text { - Experiencing/discovering new things or routes } \\
\text { - Visiting a heritage or historical site } \\
\text { - } \text { Developing leadership skills } \\
\text { - } \text { Increasing creativity } \\
\text { - } \text { Pursuing an ideology }\end{array}$ & $\begin{array}{l}\text { Barton et al. (2009); Kastenholz and Rodrigues } \\
\text { (2007); Marafa et al. (2007); Nordbø and } \\
\text { Prebensen (2015); Kim et al. (2016) }\end{array}$ \\
\hline Relaxation & $\begin{array}{l}\text { - } \text { Resting/relaxing/reviving } \\
\text { - } \quad \text { Escaping physical pressures } \\
\text { - Pursuing self-reflection, reflexivity, and self-development } \\
\text { - Seeking mental benefits }\end{array}$ & $\begin{array}{l}\text { Collins-Kreiner and Kliot (2016); Marafa et al. } \\
\text { (2007); Wolf and Wohlfart (2014) }\end{array}$ \\
\hline Travel/recreation & $\begin{array}{l}\text { - } \quad \text { Sightseeing } \\
\text { - Pursuing a new type of travel } \\
\text { - Playing games or recreating }\end{array}$ & $\begin{array}{l}\text { Barton et al. (2009); Kim et al. (2015); Wolf and } \\
\text { Wohlfart (2014) }\end{array}$ \\
\hline Socializing & $\begin{array}{l}\text { - Meeting people with same interests/new people } \\
\text { - Meeting family or friends } \\
\text { - Strengthening family ties } \\
\text { - Pursuing intimacy }\end{array}$ & $\begin{array}{l}\text { Barton et al. (2009); Collins-Kreiner and Kliot } \\
\text { (2016); Kim et al. (2015); Marafa et al. (2007); } \\
\text { Wolf and Wohlfart (2014) }\end{array}$ \\
\hline
\end{tabular}

taking risky trails (Barton et al., 2009; Kastenholz \& Rodrigues, 2007; Kim et al., 2015; Marafa et al., 2007; Nordbø \& Prebensen, 2015; Wolf \& Wohlfart, 2014). That benefit is also related to physical fitness, such as a desire to pursue a healthy lifestyle. Diverse additional benefits lead to relaxation, stress release, escape from one's routine, and recharging of one's energy (Collins-Kreiner \& Kliot, 2016; Kim et al., 2016; Marafa et al., 2007; Wolf \& Wohlfart, 2014). To illustrate these, a summary of beneficial items from the tourism literature is given in Table 1.

\section{Three-factor theory and customer delight}

According to the three-factor theory (Kano, Seraku, Takahashi, \& Tsuji, 1984; Matzler \& Sauerwein, 2002), there are three types of roles in service attributes, based on their impacts on satisfaction. First, "dissatisfiers" are the basic factors and represent the minimum requirements of customers. Those factors can lead to dissatisfaction when their performance is low, but they cannot lead to satisfaction even if their performance is high. The fulfillment of dissatisfiers is necessary to prevent customer dissatisfaction, because customers perceive those factors as being rudimentary. The second type of factor is "satisfiers," which are excitement factors that have the power to increase customer satisfaction when their performance is high. When these excitement factors perform well, they make customers surprised. They can generate delight in those customers. Third, "hybrids" are performance factors that can lead to satisfaction as well as to dissatisfaction, depending on their 
performance level (Deng, 2007; Deng, Kuo, \& Chen, 2008; Füller \& Matzler, 2008; Kano et al., 1984; Kim, Kim, \& Heo, 2016; Kim, Kim, \& Heo, 2019; Matzler, Hinterhuber, Bailom, \& Sauerwein, 1996). An important point is that the relationship between attribute performance and satisfaction is neither linear nor symmetrical for dissatisfiers and satisfiers, but it is linear and symmetrical for hybrid factors.

In the tourism literature, many studies investigate customers' and tourists' delight (Crotts, Pan, \& Raschid, 2008; Füller \& Matzler, 2008; Ma, Gao, Scott, \& Ding, 2013; Magnini, Crotts, \& Zehrer, 2011). Plutchik (1980) explains that delight is a mixture of two basic emotions in a highly activated state: joy and surprise, In addition, most previous studies seem to agree that customer delight can be obtained by experiencing positive surprise, and it has distinctive characteristics with satisfaction (Crotts \& Magnini, 2011). According to previous studies, delight can lead to positive behavioral intentions (Oliver, Rust, \& Varki, 1997; Rust \& Oliver, 2000), although that is not always the case because it seems to have a nonlinear relationship with future intentions (Fullerton \& Taylor, 2002; Mittal \& Kamakura, 2001). Torres and Kline (2006) perceive delight as a consequence of satisfaction, whereas Mikulić and Prebežac (2008) assumed that delight is an extreme level of satisfaction and frustration is an extreme level of dissatisfaction.

\section{First-time visitors and repeat visitors}

Previous research finds significant differences between the travel patterns and needs of first-time visitors and those of repeat visitors. First-time visitors in New Zealand are more likely to visit attractions and participate in tour activities, compared with repeat visitors (Oppermann, 1997). The two groups' travel motivations are also different, in the sense that first-time visitors want to explore the destination, but repeat visitors want to consume experiences in the destination (Lau \& McKercher, 2004; Li, Cheng, Kim, \& Petrick, 2008; Oppermann, 1997). Studies find that first-time visitors spend more than repeat visitors, whereas repeat visitors show a higher level of revisit intention and satisfaction than first-time visitors (Chi, 2012; Li et al., 2008; Oppermann, 1998; Petrick, 2004; Shanka \& Taylor, 2004).

Some studies are interested in identifying differences in the profiles of first-time and repeat visitors. $\mathrm{Li}$ et al. (2008) explore this topic in detail. According to Li et al. (2008), first-time visitors usually are single, female, and relatively young, while repeat visitors are married, male, and relatively mature. Obviously, first-time visitors spend more time planning their trip, and they prefer to use information from attractions and transportation sources. Decision-making by first-time visitors is influenced by friends and family, travel agents, or climate, whereas repeat visitors' decision-making is influenced mainly by cost. Shanka and Taylor (2004) also find that first-time visitors are relatively younger than repeat visitors, and their friends and family have an impact on their decisionmaking.

\section{Comparison of IRPA and IAA}

As alternative methods to IPA, Mikulić and Prebežac (2008) suggest two methods, IRPA and IAA, which can supplement the shortcomings of IPA by using derived importance - the unstandardized regression coefficient when the dependent variable is overall satisfaction. The IRPA uses a measure of the range of attributes' impacts on overall satisfaction, whereas the IAA is an approach used to analyze the asymmetry of attributes' impacts on overall satisfaction. Both the IRPA and the IAA are designed to assess an attribute's impact on overall satisfaction by comparing expectation and performance (Back, 2012). After Mikulić and Prebežac's (2008) initial introduction of the two analytical methods, some studies in the hospitality and tourism, consumer behavior, and business realms have adopted them as suitable alternatives (Back, 2012; Back \& Lee, 2015; Mikulić, Dužević, \& Baković, 2015; Woodham, Williams, \& McNeil, 2016; $\mathrm{Ye}, \mathrm{Fu}, \&$ Law, 2016). The two methods are superior to IPA because importance is assessed as the impact on satisfaction that each attribute makes. This importance measure generates reliable information for decision-makers to improve service quality attributes (Mikulić \& Prebežac, 2008).

\section{Methodology}

\section{Study setting}

The study's setting is the JOT on Jeju Island, which is located off the southwest coast of South Korea, as shown in Figure 1. Jeju Island was visited by 16 million tourists in 2016 ( $77.3 \%$ were domestic tourists, $22.7 \%$ were foreign tourists), and as such, it was the second most popular tourism destination in South Korea for foreign tourists (Jeju Tourism Association, 


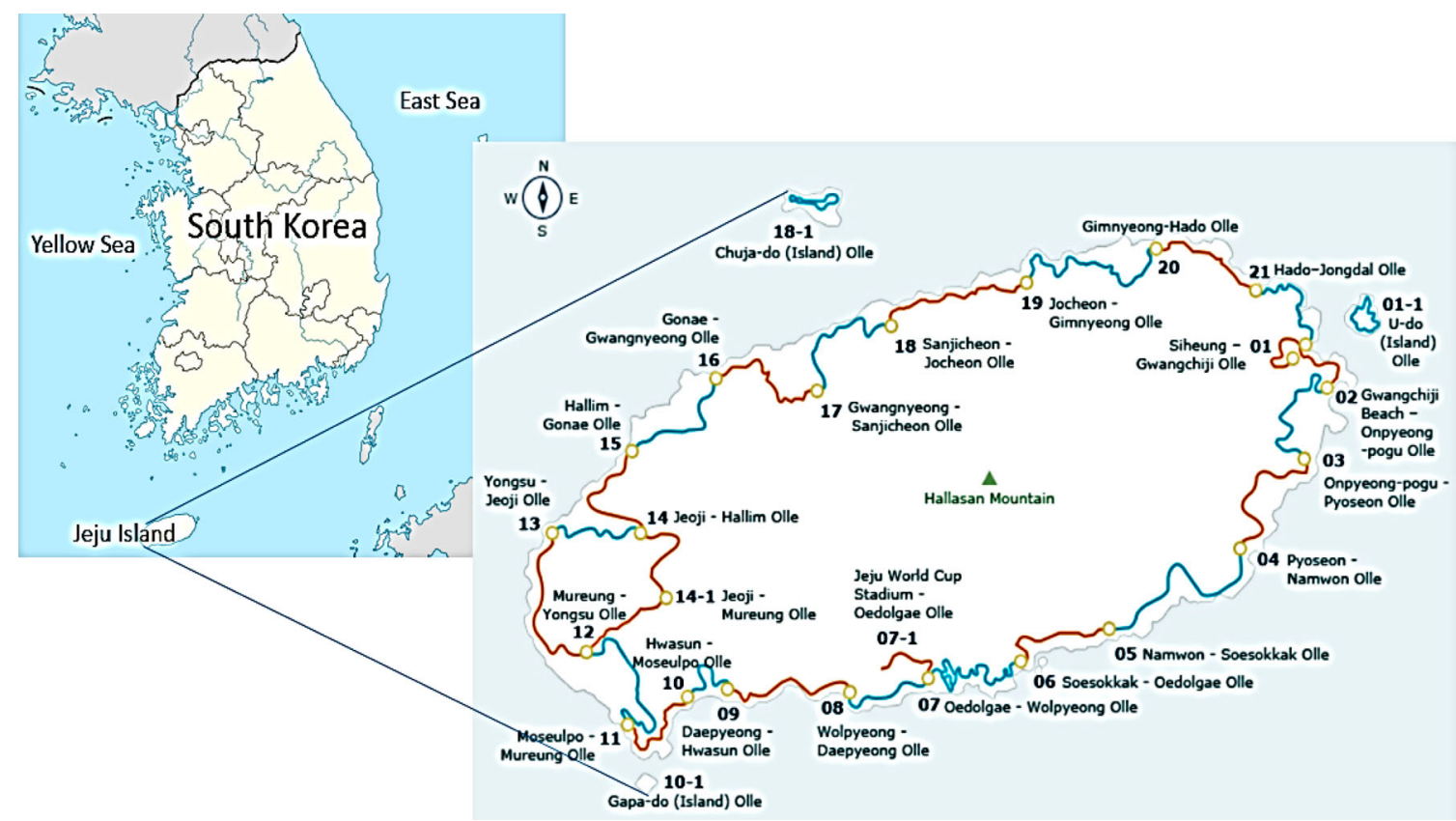

Figure 1. Location of Jeju Olle (Source: Korea Tourism Organization, Wikimedia Commons).

2017). With its blend of attractions, the JOT presents Jeju's unique topography, heritage, and local lifestyle and culture for the sophisticated nature lover. Jeju Island itself was formed from volcanic activity and has 368 volcanic cones speckled across the island, with Halla Mountain as the center. This island is a recipient of four awards from UNESCO in the subject category of natural science.

The JOT was initiated by the Jeju Olle Incorporated Association in September 2007, to benchmark the Camino de Santiago, a famous pilgrimage trail in Spain. As of February 2018, the JOT consisted of 26 courses, with 21 connected main routes and 5 subroutes, along the coastline of Jeju Island (see Figure 1). In total, the JOT spans $425 \mathrm{~km}$ in length, with each course straddling between four and six walking hours. The word "Olle" originated from a Jeju dialect word meaning "a narrow road leading up to the gate of a house from the main street" (Hyun, Park, \& Kim, 2016). The JOT encourages out-ofisland travelers to stay longer and creates spending on the island (Kim et al., 2015).

\section{Survey design and data collection}

The study used a questionnaire, the first section of which was related to the benefits of the JOT. As
Table 1 indicates, the list of benefit items was extracted from previous studies. However, because all items do not fit well to the JOT setting due to its different geological/cultural/recreational/touristic characteristics, only items featuring trails were selected. In addition, from a methodological perspective, too many items may lead to complicated and confusing interpretation of the IRPA and IAA results. Thus, inclusion of a parsimonious set of items is better than inclusion of many items (Mikulić et al., 2015). Results of executing a pilot test using 25 hikers on the JOT led us to include the benefit items "enjoy local food" and "buy unique souvenirs of the JOT." A total of 18 benefits from the JOT were identified, relating to benefits from being in nature (2 items), education/culture (5 items), relaxation (2 items), socializing ( 2 items), traveling (6 items), and being active (1 item). In addition, respondents were required to quantify their expectations for the 18 items that comprised the benefits from hiking the trail and to rate the performance of each of those items.

Examples of such questions are "Please tick the number indicating the level of importance that you consider regarding the benefit gained from hiking the JOT" and "Please tick the number indicating 
the level of performance that this trail provides regarding the benefit gained from hiking the JOT." One item to measure overall satisfaction was operationalized as "Please tick the number indicating your overall satisfaction level, based on your experience hiking the JOT." Responses to identify importance, performance, and overall satisfaction were measured with 5-point Likert-type scales, where "1" indicated strongly disagree, " 3 " was neutral, and " 5 " was strongly agree. Items requesting demographics and general travel profiles were measured as categorical variables.

Because this study assumed that the characteristics of travelers in all courses were similar to each other, data were collected at two courses of the JOT: at the end of Courses 5 and 7. The reason why the two courses were selected was they were most well-known to hikers and have the highest demand of hiking. Three interviewers, who were briefed on the purpose of this study, participated in the data collection procedure. Data were collected on weekdays and weekends for three weeks in June 2016 as profiles of hikers can be different according to the day of the week.

To select appropriate samples, a systematic sampling method was adopted by intercepting every 10th hiker walking on the trail to capture responses from different groups, even though a group size was diverse. The survey was administered at the end of the hiking courses and it took about 10-15 minutes. Because the study population was 18 year or older Korean hikers out of the island, one screening question asked whether the hiker was a non-resident of the island. As an incentive to enhance the participation rate, Jeju chocolates were offered as a token of gratitude. Among a total of 322 respondents who completed the questionnaire, 318 responses were used for further data analyses. The first-time visitors constituted $45.3 \%$ of the sample, whereas $54.7 \%$ of the respondents were repeat visitors.

\section{Computation of IRPA and IAA}

The major procedures and equations of the IRPA and IAA methods were as follows.

Two sets of variables are made: one of which was a set of low-performance cases and the other was a set of high-performance cases. Then, multiple regressions were run using two sets of dummy variables as independent variables and overall satisfaction as the dependent variable. The reward index (RI) is the unstandardized regression coefficients of the dummy variables of high performance, while the penalty index is the unstandardized regression coefficients of the dummy variables of low performance. A two-dimensional grid is constructed with RIOCS on the horizontal axis and performance on the vertical axis. The grid is divided into four quadrants, using the grand means as the axes.

A two-dimensional grid is constructed with the impact asymmetry scores on the vertical axis and the RIOCS values on the horizontal axis. The horizontal axis is divided into five parts, according to the degree of impact asymmetry on overall satisfaction: "delighters" (IA index $>0.40)$, "satisfiers" $(0.40 \geq \mid \mathrm{A}$ index $>$ $0.10)$, "hybrids" $(0.10 \geq I A$ index $\geq-0.10)$, "dissatisfiers" $(-0.10>$ IA index $\geq-0.40)$, and "frustrators" (IA index $<-0.40)$. The RIOCS is set according to the distribution of attributes (Back, 2012; Ye et al., 2016). The criteria of IA index and RIOCS values for classifying five parts on the horizontal axis and three parts on the vertical axis followed the recommendations of previous studies (Mikulić \& Prebežac, 2008; Mikulić \& Prebežac, 2012).

\section{Results}

\section{Profile of respondents}

Among first-time visitors, $58.0 \%$ of the respondents were females, and $70.9 \%$ were married. Respondents in their 50s (28.4\%) and company-employee respondents (29.2\%) were the highest proportion, respectively, in the age and occupation groups. On the contrary, of the repeat visitors, $53.8 \%$ were female and $77.8 \%$ were married. Repeat visitors were more likely to be in their 40s (31.6\%) and housewives (21.8\%). According to the Chi-square tests, repeat visitors were more educated and had higher incomes than first-time visitors. First-time visitors were more likely to visit alone than repeat visitors. Detailed information is displayed in Table 2.

\section{Exploratory factor analysis on the performance of the benefits sought}

Eighteen items depicting different benefits from the hiking experience were measured. In order to look into the structures of data, to summarize the information, and to refine superfluous items, exploratory factor analysis (EFA) using varimax rotation was conducted. However, since three items showed a low level of communalities (less than 0.40) these items were deleted. In addition, two items were ruled out 
Table 2. Profile of the respondents.

\begin{tabular}{|c|c|c|c|c|}
\hline Variables & Category & $\begin{array}{l}\text { First-time visitors }(n=144) \\
\%\end{array}$ & $\begin{array}{l}\text { Repeat visitors }(n=174) \\
\%\end{array}$ & $x^{2}$ ( $p$-value) \\
\hline \multirow[t]{2}{*}{ Gender } & Female & 58.0 & 53.8 & $.43(.512)$ \\
\hline & Male & 42.0 & 46.2 & \\
\hline \multirow[t]{2}{*}{ Marriage } & Married & 70.9 & 77.8 & $1.55(.213)$ \\
\hline & Not married & 29.1 & 22.2 & \\
\hline \multirow[t]{5}{*}{ Age } & 20 s or younger & 14.8 & 12.4 & $2.15(.708)$ \\
\hline & $30 \mathrm{~s}$ & 21.6 & 19.1 & \\
\hline & $40 s$ & 23.9 & 31.6 & \\
\hline & $50 \mathrm{~s}$ & 28.4 & 24.4 & \\
\hline & 60 s or older & 11.4 & 12.4 & \\
\hline \multirow[t]{2}{*}{ Educational level } & Senior high school or below & 43.0 & 29.2 & $5.26^{*}(.022)$ \\
\hline & Undergraduate college or above & 57.0 & 70.8 & \\
\hline \multirow[t]{4}{*}{ Household income } & US\$24,000 or less & 26.0 & 28.6 & $8.10^{*}(.044)$ \\
\hline & US\$24,001-\$40,000 & 45.5 & 25.5 & \\
\hline & US\$40,001-\$63,000 & 16.9 & 34.7 & \\
\hline & More than US\$63,000 & 11.7 & 11.2 & \\
\hline \multirow{6}{*}{ Occupation } & Company employee & 29.2 & 21.3 & $4.37(.497)$ \\
\hline & Civil servant & 5.6 & 10.4 & \\
\hline & Housewife & 16.9 & 21.8 & \\
\hline & Professional & 18.0 & 19.0 & \\
\hline & Sales/service & 11.2 & 9.0 & \\
\hline & Others & 19.1 & 18.5 & \\
\hline \multirow[t]{5}{*}{ Type of companions } & Alone & 5.8 & 5.3 & $4.05(.399)$ \\
\hline & Friend/Lover & 43.0 & 37.3 & \\
\hline & Family & 26.7 & 37.3 & \\
\hline & College & 18.6 & 12.9 & \\
\hline & Others & 5.8 & 7.2 & \\
\hline \multirow[t]{5}{*}{ Number of companions } & 1 & 18.8 & 4.0 & $22.57^{* * *}(.000)$ \\
\hline & 2 & 15.0 & 19.5 & \\
\hline & 3 & 8.8 & 20.0 & \\
\hline & 4 & 6.3 & 12.0 & \\
\hline & 5 or more & 51.3 & 44.5 & \\
\hline \multirow[t]{3}{*}{ Length of stay } & 1 night & 42.0 & 46.2 & $.44(.801)$ \\
\hline & 2 nights & 31.8 & 29.0 & \\
\hline & 3 nights or longer & 26.1 & 24.8 & \\
\hline \multirow[t]{6}{*}{ Accommodations } & 5-star hotel & 14.1 & 15.7 & $.63(.986)$ \\
\hline & 4-star hotel & 20.5 & 19.6 & \\
\hline & Low-quality hotel & 5.1 & 4.6 & \\
\hline & Local guesthouse & 20.5 & 17.0 & \\
\hline & Relative's house & 9.0 & 9.8 & \\
\hline & Other & 30.8 & 33.3 & \\
\hline
\end{tabular}

Note: ${ }^{*} p<.05,{ }^{* *} p<.01,{ }^{* * *} p<.001$.

because "Cronbach's alpha if the items deleted with extracted factors" were higher than overall Cronbach's alpha.

As shown in Table 3, results of the factor analysis using 13 items produced a four-factor structure which exceeded eigenvalues of 1.0. The amount of the explained variance within each domain was $22.11 \%, 16.68 \%, 15.10 \%$, and $14.11 \%$. All factor loadings are close to or higher than 0.44 , as recommended by Comrey and Lee (1992). Communalities for each item which present the variances accounted for by the factors ranged from 0.57 to 0.84 . The value of the Kaiser-Meyer-Olkin (KMO) measure of sampling adequacy was 0.89 , confirming validation of the factor model. Results of Barlett's test of sphericity showed significance $(p=.000)$, indicating the existence of one or more factors. All Cronbach's alpha values were higher than criterion (.70) recommended by Nunnally (1978). The extracted factors were labeled escape and relaxation (Domain 1), experience of regional culture (Domain 2 ), interaction benefit (Domain 3), and educational benefit (Domain 4).

\section{Results of impact-range performance analysis}

The IRPA uses stated performance as well as implied importance to identify the impact of benefit attributes 
Table 3. Exploratory factor analysis of the performance of the benefits sought $(n=318)$.

\begin{tabular}{|c|c|c|c|}
\hline Escape and relaxation (eigenvalue $=2.87 ; 22.11 \% ; \alpha=.80$ ) & Factor loadings & Communalities & Mean \\
\hline Observing fantastic natural landscape & .82 & 69 & 4.07 \\
\hline Being away from daily life & .81 & 69 & 4.05 \\
\hline Feeling relaxed & .70 & 61 & 3.90 \\
\hline Maintaining good health & .70 & .67 & 4.04 \\
\hline Being away from commercial areas & .51 & .44 & 3.50 \\
\hline Experience of regional culture (eigenvalue $=2.17 ; 16.68 \% ; a=.75$ ) & Factor loadings & Communalities & Mean \\
\hline Enjoying local food & .76 & .70 & 3.35 \\
\hline Being close to other tourist attractions & .74 & .67 & 3.48 \\
\hline Buying unique souvenirs of Jeju Olle Trail & .74 & .74 & 2.88 \\
\hline Interaction benefit (eigenvalue $=1.97 ; 15.10 \% ; a=.82$ ) & Factor loadings & Communalities & Mean \\
\hline Meeting people and interacting with them & .86 & .84 & 3.29 \\
\hline Having an opportunity to meet new people & .79 & .80 & 3.07 \\
\hline Educational benefits (eigenvalue $=1.84 ; 14.11 \% ; a=.73$ ) & Factor loadings & Communalities & Mean \\
\hline Experiencing the virtual life of residents & .81 & .77 & 3.27 \\
\hline Enjoying the cultural value by visiting museums and events & .71 & .67 & 3.04 \\
\hline Satisfying intellectual curiosity & .44 & .57 & 3.31 \\
\hline
\end{tabular}

Note: A response was measured as "strongly disagree" (1), "neutral" (3), and "strongly agree" (5).

on overall satisfaction. In Table 4 RIOCS indicates the sum of penalty indices (PI) and reward indices (RI) for each benefit attribute. As RIOCS represents incremental changes of each dependent variable, a high value of RIOCS indicates a high impact in case of extremely high and extremely low performance. For the first-time visitor group, the highest RIOCS value was found on "overseeing fantastic natural landscape" (2.29), "buying unique souvenirs of Jeju Olle Trail" (2.11), "meeting people and interacting with them" (1.66), and "having an opportunity to meet new people" (1.61), and "experiencing the high virtual life of residents" (1.61). However, for the repeat visitor group, "feeling relaxed" (1.09) showed a relatively high value of RIOCS.

As shown in Figure 2, results of the IRPA showed different patterns between first-time visitors and repeat visitors. For example, "observing fantastic natural landscape" is situated into the category of high impact-high performance for first-time visitors, whereas "feeling relaxed" is located in the category of high impact-high performance for repeat visitors. In the quadrant of low impact-high performance, "being away from daily life", "maintaining good health" were commonly located for both cohorts. Interestingly, "satisfying intellectual curiosity" was placed in the low-impact-low performance quadrant for the first-time visitor group, whereas it was located in the high impact-low performance quadrant for the repeat visitor group. "Meeting people and interacting with them" and "experiencing the virtual life of residents" were located in a category of high impact-low performance for the first-time visitor group whereas these attributes belonged to a low impact-low performance quadrant for the repeat visitors group.

For the first-time visitor group, "being away from commercial area", "enjoying local food", "satisfying intellectual curiosity", "enjoying the cultural value by visiting museums and event" are located in the low impact-low performance category. However, for the repeat visitor group "enjoying local food", "experiencing the virtual life of resident", "meeting the cultural value by visiting museums and events", and "enjoying the cultural value by visiting museums and events" fall into the low impact-low performance quadrant.

Finally, the pattern of benefit attributes was different between the first visitor and repeat visitor groups. "Being close to other tourism attractions", "meeting people and interacting with them", "experiencing the virtual life of residents", "having an opportunity to meet new people" and "buying unique souvenirs of Jeju Olle Trail" were located in the high impact-low performance quadrant for the first-time visitor group. However, "satisfying intellectual curiosity", "having an opportunity to meet new people", and "buying unique souvenirs of Jeju Olle Trail" were placed in the high impact-low performance category for the repeat visitor group.

\section{Results of impact-asymmetry analysis}

Results of undertaking IAA are presented in Table 4 and Figure 3 . The value of (highest RIOCS-lowest $\mathrm{RIOCS} / 2\}$ is defined as a cutoff between low and medium impact, and the value of (highest RIOCSlowest RIOCS) is defined as a cutoff between medium and high impact (Mikulić et al., 2015). 
Table 4. Results of the IRPA and IAA.

\begin{tabular}{|c|c|c|c|c|c|c|c|}
\hline \multicolumn{8}{|c|}{ First-time visitors $(n=144)$} \\
\hline Domains and items of benefits & $\mathrm{RI}$ & $\mathrm{PI}$ & RIOCS & SGP & DGP & IA & Factor \\
\hline \multicolumn{8}{|l|}{ Escape and relaxation } \\
\hline Observing fantastic natural landscape & -.07 & -2.22 & 2.29 & .03 & .97 & -.94 & Frustrator \\
\hline Being away from daily life & .74 & -.08 & .82 & .91 & .09 & .81 & Delighter \\
\hline Feeling relaxed & -.64 & .30 & .95 & .68 & .32 & .36 & Satisfier \\
\hline Maintaining good health & -.57 & .23 & .80 & .72 & .28 & .43 & Delighter \\
\hline Being away from commercial areas & .98 & -.10 & 1.08 & .90 & .10 & .81 & Delighter \\
\hline \multicolumn{8}{|l|}{ Experience of regional culture } \\
\hline Enjoying local food & -.39 & .08 & .47 & .82 & .18 & .65 & Delighter \\
\hline Being close to other tourist attractions & .26 & -1.10 & 1.37 & .19 & .81 & -.61 & Frustrator \\
\hline \multicolumn{8}{|l|}{ Interaction benefit } \\
\hline Meeting people and interacting with them & -.73 & .94 & 1.66 & .44 & .56 & -.13 & Dissatisfier \\
\hline Having an opportunity to meet new people & -.72 & -.88 & 1.61 & .45 & .55 & -.10 & Hybrid \\
\hline $\begin{array}{l}\text { Educational benefit } \\
\text { Experiencing the virtual life of residents }\end{array}$ & 1.33 & -.22 & 1.56 & .86 & 14 & Educational benefit & Delighter \\
\hline Enjoying the cultural value by visiting museums and events & .92 & .15 & 1.06 & .86 & .14 & .73 & Delighter \\
\hline Satisfying intellectual curiosity & -.87 & .13 & 1.00 & .87 & .13 & .75 & Delighter \\
\hline \multicolumn{8}{|l|}{ Repeat visitors $(n=174)$} \\
\hline \multicolumn{8}{|l|}{ Escape and relaxation } \\
\hline Observing fantastic natural landscape & .28 & .05 & .33 & .86 & .14 & .72 & Delighter \\
\hline Being away from daily life & .31 & -.13 & .44 & .70 & .30 & .41 & Delighter \\
\hline Feeling relaxed & -.15 & -.94 & 1.09 & .14 & .86 & -.73 & Frustrator \\
\hline Maintaining good health & .21 & -.03 & .24 & .86 & .14 & .72 & Delighter \\
\hline Being away from commercial areas & .20 & .02 & .22 & .92 & .08 & .84 & Delighter \\
\hline \multicolumn{8}{|l|}{ Experience of regional culture } \\
\hline Enjoying local food & .31 & .12 & .42 & .73 & .27 & .46 & Delighter \\
\hline Being close to other tourist attractions & -.17 & -.35 & .52 & .33 & .67 & -.34 & Dissatisfier \\
\hline $\begin{array}{l}\text { Buying unique souvenirs of Jeju Olle Trail } \\
\text { Interaction benefit }\end{array}$ & .52 & -.04 & .56 & .93 & .07 & .86 & Delighter \\
\hline Meeting people and interacting with them & .25 & .04 & .29 & .86 & .14 & .72 & Delighter \\
\hline \multicolumn{8}{|l|}{ Educational benefit } \\
\hline Experiencing the virtual life of residents & .05 & -.17 & .22 & .24 & .76 & -.52 & Frustrator \\
\hline Enjoying the cultural value by visiting museums and events & .07 & -.13 & .20 & .34 & .66 & -.31 & Dissatisfier \\
\hline Satisfying intellectual curiosity & -.55 & .15 & .71 & .78 & .22 & .57 & Delighter \\
\hline
\end{tabular}

Note: $\mathrm{RI}$ and $\mathrm{PI}$ are unstandardized regression coefficients.

$\mathrm{RI}=$ reward indices, $\mathrm{PI}=$ penalty indices, $\mathrm{RIOCS}=|\mathrm{RI}|+|\mathrm{PI}|, \mathrm{SGP}=\mid$ reward index $|/ \mathrm{RIOCS}, \mathrm{DGP}=|$ penalty index $\mid / \mathrm{RIOCS}, \mathrm{IA}=\mathrm{SGP}-\mathrm{DGP}$.

Frustrators and dissatisfiers can be interpreted as fundamental elements, whereas delighters and satisfiers are excitement factors of service experiences, according to the three-factor theory (Kano et al., 1984; Matzler \& Sauerwein, 2002).

For first-time visitors, the benefit of "observing fantastic natural landscape" was the most impactful basic benefit of their hiking experience on the JOT, thus revealing it as a high-impact frustrator. The next most important fundamental benefits for first-time visitors were "being close to other tourist attractions" and "meeting people and interacting with them". Those benefits were identified, respectively, as a medium-impact frustrator and a medium-impact dissatisfier. For repeat visitors, the benefit of "feeling relaxed" was a high-impact frustrator and represents the most impactful and fundamental benefit. The next most impactful basic benefits for repeat visitors were "being close to other tourist attractions" (a medium-impact dissatisfier), "experiencing the virtual life of residents" (a low-impact frustrator), and "enjoying the cultural value by visiting museums and events" (a low-impact dissatisfier). Those benefits were basic needs for hikers on the JOT, which means the hikers will experience dissatisfaction when they cannot get those benefits from their hiking experience, but at the same time they will not be satisfied even if the performance on these attributes is high because they take those benefits for granted.

The comparison of frustrators and dissatisfiers between first-time and repeat visitors notes that first-time visitors' fundamental hiking benefits are nature, additional tours, and interactions, whereas repeat visitors' basic needs are relaxation, additional 

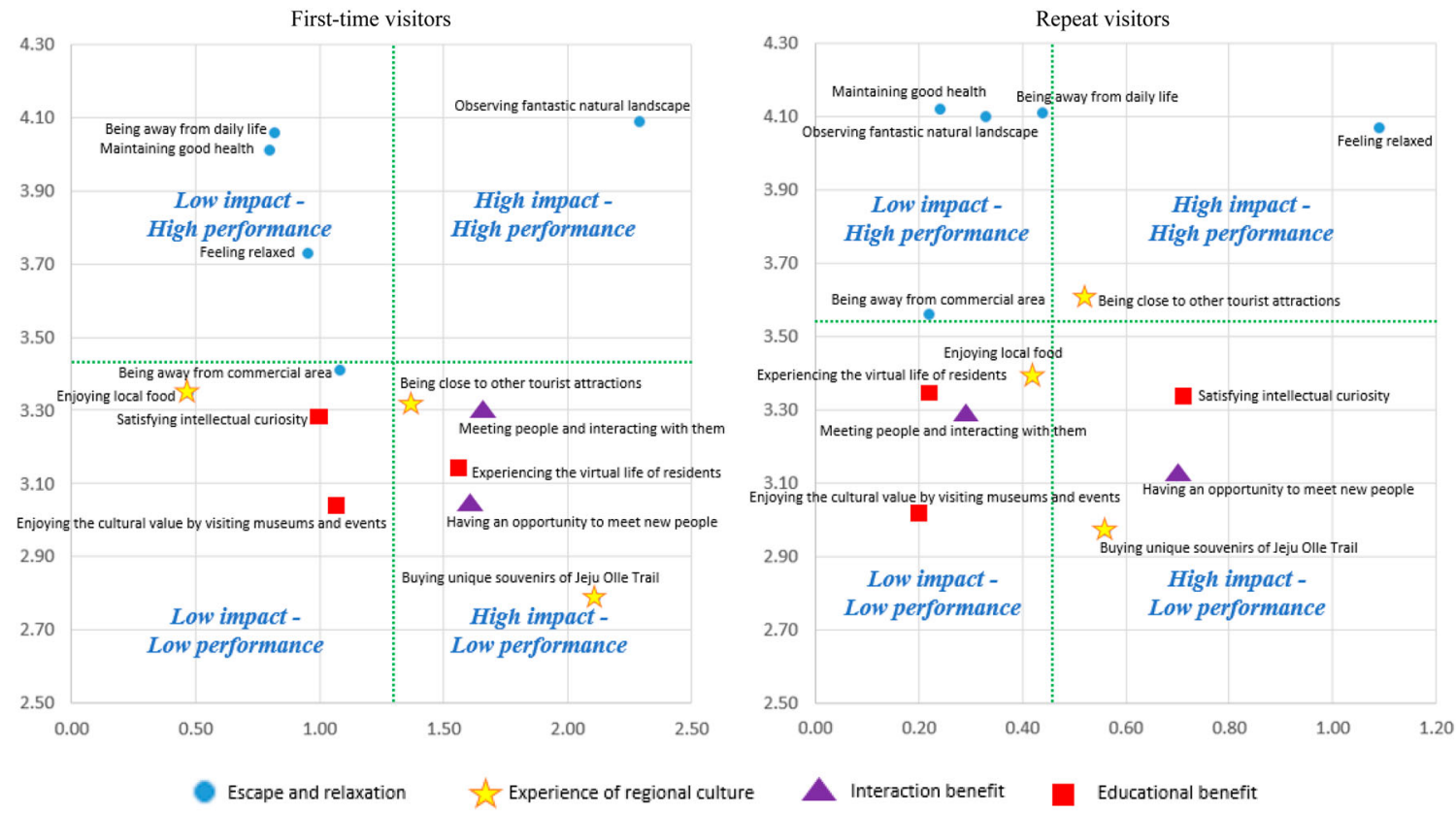

Figure 2. Results of the IRPA.
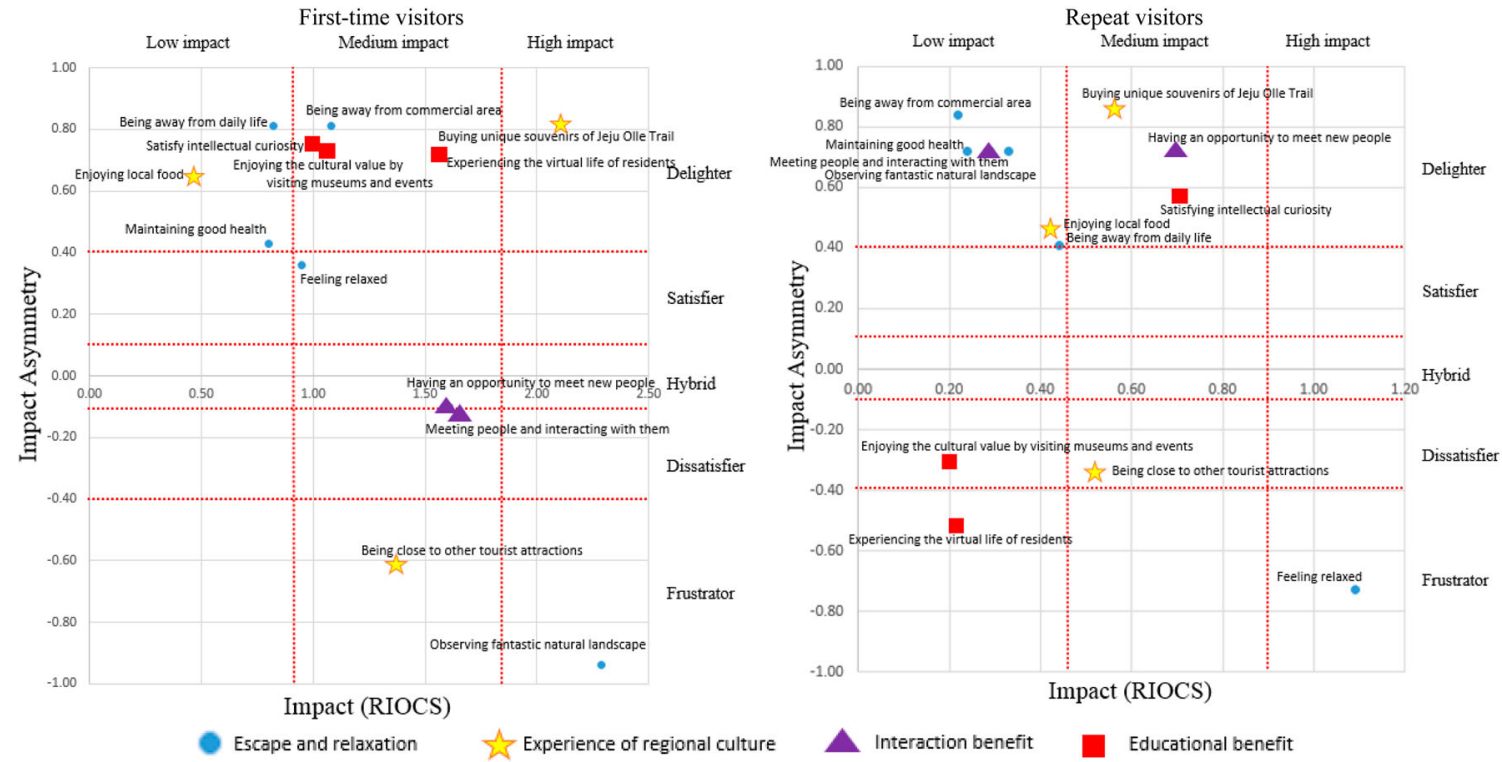

Figure 3. Results of the IAA. Note: The value of $\{$ (highest RIOCS-lowest RIOCS)/2 $\}$ was defined as a cutoff between low and medium impact, whereas the value of (highest RIOCS-lowest RIOCS) was defined as a cutoff between medium and high impact.

tours, and education. The hiking benefit of "having an opportunity to meet new people" was revealed as a medium-impact hybrid attribute for first-time visitors, indicating that this benefit can lead to either satisfaction or dissatisfaction, according to its performance level. However, hybrid benefits were not discovered for repeat visitors.

First-time visitors addressed that "buying unique souvenirs of the JOT" was the most exciting benefit of their hiking experience - a fact that makes it a 
high-impact delighter. In a similar vein, first-time visitors indicated that the next most important/exciting benefits were "experiencing the virtual life of residents", "being away from commercial areas", "enjoying cultural values by visiting museums and events", and "satisfying their intellectual curiosity". Moreover, the benefit of "feeling relaxed" was classified as a medium-impact satisfier, while three benefits were low-impact-delighters: "being away from daily life", "enjoying local food", and "maintaining good health".

For repeat visitors, no high-impact delighters were identified, whereas there were three excitement benefits indicating medium-impact delighters: "satisfying intellectual curiosity", "having an opportunity to meet new people", and "buying unique souvenirs of the JOT". Additionally, low-impact delighters were observed on four hiking benefits: "observing fantastic natural landscape", "meeting people and interacting with them", "maintaining good health", and "being away from commercial areas". This indicates that those underlying pent-up needs can generate excitement for hikers on the JOT. Therefore, hikers can experience satisfaction when they get those benefits from their hiking experience but the absence of these benefits did not cause dissatisfaction, because they consider those benefits to be superfluous. Interestingly, hybrid benefits were not found on IAA graph shown in Figure 3 for both groups.

\section{Discussion and implications}

\section{Discussion}

Among the diverse findings of this study, several significant points stand out. First, the results of the IRPA and the IAA indicate different perceptual patterns between first-time visitors and repeat visitors. For example, the first-time visitor group indicate a high impact in the case of extremely high and extremely low performance on "overseeing fantastic natural landscape" (2.29), "buying unique souvenirs of Jeju Olle Trail" (2.11), "meeting people and interacting with them" (1.66), and "having an opportunity to meet new people" (1.61), and "experiencing the high virtual life of residents" (1.61). However, the repeat visitor group reveal that "feeling relaxed" (1.09) shows a relative high value of RIOCS. As a result, repeat visitors demonstrate less sensitivity to benefit factors because they are more satisfied with the trail compared to first-time visitors.

Second, a comparison of perceptual maps between first-time visitors and repeat visitors reveal differences in some benefits. For example, "observing fantastic natural landscape" is found in the category of high impact-high performance for first-time visitors, whereas it is identified in the category of low impact-high performance for repeat visitors. That is, first-time visitors perceive this benefit as important and rate this benefit highly, whereas repeat visitors perceive this benefit as important but perceive lower benefits from this attribute perhaps because they have experienced this landscape previously.

Third, first-time visitors report that "satisfying intellectual curiosity" is considered relatively unimportant but did report high performance by the JOT management. However, repeat visitors are not dissatisfied with this benefit even though this benefit is important to them. The results imply that repeat visitors seek intellectual or knowledge activities through walking this trail. Thus, the two groups showed different drivers of benefits.

Fourth, overall, both groups exhibit dissatisfaction with "having an opportunity to meet new people" and "buying unique souvenirs of the trail" even though they seek these benefits. Thus, the trail management should make every effort to enhance these two benefits. Interestingly, the two cohorts reveal different evaluation of benefits which are considered important and perform well. For example, first-time visitors report high satisfaction on "observing fantastic natural landscape" because they believe this benefit is important. However, repeat visitors report high satisfaction with "feeling relaxed" and "being close to other tourist attractions" because they believe these benefits are of significance.

Fifth, results of conducting the IAA show distinct patterns between the two groups. For example, "feeling relaxed" is a satisfier with first-time visitors, whereas this benefit is considered a frustrator by repeat visitors. That is, first-time visitors report they seek "feeling relaxed" from hiking, whereas repeat visitors are dissatisfied if this benefit is not provided. Thus the trail management needs to offer facilities nearby the trail such as a shelter or a local food restaurant, or a local massage center to visitors.

Sixth, first-time visitors experience satisfaction with the hiking experience when they can socialize with family, friends, and even with new people, or can experience local life and products, whereas repeat visitors are satisfied when they actually get a chance meet new people or they gain knowledge during their hiking experience. Benefits that delight both groups of hikers are shopping for local goods. Thus, gift 
shops emphasizing locality or providing traditional crafts need to be offered.

Seventh, an exciting benefit for first-time visitors is experiencing the virtual life of residents, whereas repeat visitors show a high level of dissatisfaction with experiencing the virtual life of residents. Thus the findings demonstrate that repeat visitors want to identify more closely with the local residents' life compared to first-time visitors. Thus, in developing trail guidelines, the trail authorities need to recommend that repeat visitors choose trail courses where there is accessibility to villages and where they can experience local culture/tradition. This means hikers' preference for seeking an educational experience such as novelty-seeking or knowledge-seeking through walking the trail in the island. Since the island has unique and exotic geological features and customs (Woo et al., 2013), repeat visitors want to deepen their experience through being involved with the local community while hiking the trail.

\section{Academic and practical implications}

This study provides three major contributions to the extant tourism literature. First, this study reflects current trends that eco-friendly or sustainable tourism is prevalent. Hiking helps hikers to seek physical and mental wellness, love for greenspace, and cultural and adventurous tourism (Barton et al., 2009; Kastenholz \& Rodrigues, 2007; Maas, Verheij, Groenewegen, De Vries, \& Spreeuwenberg, 2006; Marcus \& Barnes, 1999; Moore \& Ross, 1998). The combination of these traits provides an academic imperative to analyze this field as a sustainable practice of community tourism development and sustainability. Specially, this study augments knowledge about the benefits that hiking tourists seek. The fact the trail is located on an island means that hiking benefits are different from previous studies which emphasize escape and relaxation, the experience of regional culture, an interaction benefit, health, and an educational benefit. Therefore, the aim of this study is to provide deeper and better explorations into an understanding of hiking tourism benefits by utilizing different analytical frameworks.

Second, this research is the initial attempt to compare first-time and repeat visitors in the context of hiking tourism. In the tourism literature, a number of studies relate to hiking benefits, however, no effort has been made to investigate the hiking benefits for first-time and repeat visitors, although previous work discovered that their behaviors differ markedly, as does the implication for those behaviors in marketing planning (Chi, 2012; Kozak, 2001; Oppermann, 1998). The results of this study confirm that differences exist in the underlying needs that firsttime and repeat visitors seek from their hiking experience. Therefore, the trail management needs to offer different programs or guidelines to the two groups. This will lead to satisfaction with their experience and support of the trail development. A future study needs to investigate their assessment of the trail and future hiking intentions.

Third, by applying two different analytical approaches, this study generates the perceived benefits for hikers, from various angles. To achieve that, the IRPA and IAA were conducted to overcome the drawbacks of IPA, the traditional method of analysis (Back, 2012; Mikulić \& Prebežac, 2008; Ye et al., 2016). By using these new techniques, our study confirms that the three-factor theory can be used and expanded to help explain the roles that different hiking benefit attributes play in determining satisfaction.

The findings of this study suggest practical implications for fostering sustainable development management. Now that a decade has elapsed since the JOT began, the development of shops, restaurants, and other auxiliary attractions, including leisure facilities, is becoming increasingly evident near the trail. In contrast, our results show that visitors, especially firsttime visitors, feel that being away from commercial areas delights them. Interestingly, results of this study indicate hikers' interest in the authenticity of local communities and natural benefits along the JOT.

In order to prioritize the JOT's attributes for effective satisfaction management based on this study's findings, the trail authorities need to generate and employ a more feasible presentation about the benefits that hikers can obtain from the hiking trail. For instance, event planners need to develop promotional materials that highlight the trail's educational value and pleasant experiential value, especially for the first-time visitors, while the materials need to emphasize interaction opportunities for repeat visitors.

The benefits of shopping for local goods can be emphasized in order to maximize the effectiveness of promotional efforts, since buying souvenirs is revealed to be a high-impact source of delight for first-time visitors and a medium-impact source of delight for repeat visitors. Moreover, Jeju Island 
needs to focus on prolonging the length of stay of repeat visitors who want relaxation from their hiking tourism, to support sustainable tourism that has local residents near to the JOT. Introducing local culture and interacting with tourists, and supporting residents who want to create more income will provide substantial benefits to hikers.

Based on the findings, there is a need to develop a walking festival, educational events, volunteer opportunities and cultural events every year to highlight and promote social and educational benefits, which create excitement for visitors. These efforts can help enhance brand value and loyalty to the destination (Kim, Choe, \& Petrick, 2018; Kim, Schuckert, Im, \& Elliot, 2017).

As a fundamental need, because both groups want to explore more attractions on Jeju Island, information about attractions near the JOT should be provided in promotional materials including QR codes which can be placed on current signs to direct hikers to further information which can be accessed over the Internet, for interested hikers. Furthermore, now that visitors, especially first-time visitors, demonstrate a preference for more authentic experiences, such as experiencing local food and local products, there is a need to showcase residents' virtual life because Jeju Island has a unique culture and lifestyle from the view of outsiders.

As Figure 2 shows, repeat visitors indicated interaction benefit and educational benefit as high impact-low performance. Therefore the JOT management need to offer educational value through adopting interpretation or environment program and more opportunities to intermingle with other hikers through holding a hiking event or meeting of like-minded hiking associations. For first-time visitors programs which introduce local culture or heritage site along the trail are needed to be introduced to showcase virtual life of residents and encounter new island tradition.

\section{Study limitations and suggestions for future study}

This study is vulnerable to several imitations. First, data collection was administered on only two trail courses which are most popular to hikers. Thus, a future study could be conducted on other courses to compare the results, in order to explore whether the results from different courses are similar or different. Second, this study was designed to identify benefits to domestic visitors. A future study needs to examine the benefits sought by international tourists.
Third, it is recommended to undertake qualitative research among hikers to better understand the reasons why they go hiking and what kind of improvements JOT can make in order to enhance the hiking experience. Fourth, five items were deleted in the process of factor analyzing and thus a future study needs to identify how the results are different when including these items in other study settings. Last, our comparison of results using two distinctive methods needs to be extended to other types of tourism in order to understand the benefits sought and enjoyed by groups who participate in specialinterest tourism, such as wildlife watching, adventure tourism, gaming, or food tourism.

\section{Disclosure statement}

No potential conflict of interest was reported by the authors.

\section{ORCID}

Seongseop (Sam) Kim (D) http://orcid.org/0000-0002-9213-6540 Stephen Pratt (1) http://orcid.org/0000-0002-6550-132X

\section{References}

Adongo, R., \& Kim, S. (2018). Whose festival is it anyway? Analysis of festival stakeholder power, legitimacy, urgency, and the sustainability of local festivals. Journal of Sustainable Tourism, 26(11), 1863-1188.

Adongo, R., Kim, S., \& Elliot, S. (2019). "Give and take": A social exchange perspective on festival stakeholder relations. Annals of Tourism Research, 75(1), 42-57.

Back, K. J. (2012). Impact-range performance analysis and asymmetry analysis for improving quality of Korean food attributes. International Journal of Hospitality Management, 31(2), 535543.

Back, K. J., \& Lee, C. K. (2015). Determining the attributes of casino customer satisfaction: Applying impact-range performance and asymmetry analyses. Journal of Travel \& Tourism Marketing, 32(6), 747-760.

Barton, J., Hine, R., \& Pretty, J. (2009). The health benefits of walking in greenspaces of high natural and heritage value. Journal of Integrative Environmental Sciences, 6(4), 261-278.

Chi, C. G. (2012). An examination of destination loyalty: Differences between first-time and repeat visitors. Journal of Hospitality \& Tourism Research, 36(1), 3-24.

Collins-Kreiner, N., \& Kliot, N. (2016). Particularism vs. universalism in hiking tourism. Annals of Tourism Research, 56(3), 132-137.

Comrey, A., \& Lee, H. (1992). A first course in factor analysis (2nd ed.). Hillsdale, NJ: Lawrence Erlbaum.

Crotts, J. C., \& Magnini, V. P. (2011). The customer delight construct: Is surprise essential? Annals of Tourism Research, 38 (2), 719-722. 
Crotts, J. C., Pan, B., \& Raschid, A. E. (2008). A survey method for identifying key drivers of guest delight. International Journal of Contemporary Hospitality Management, 20(4), 462-470.

Deng, W. (2007). Using a revised importance-performance analysis approach: The case of Taiwanese hot springs tourism. Tourism Management, 28(5), 1274-1284.

Deng, W. J., Kuo, Y. F., \& Chen, W. C. (2008). Revised importanceperformance analysis: Three-factor theory and benchmarking. The Service Industries Journal, 28(1), 37-51.

Freidt, B., Hill, E., Gómez, E., \& Goldenberg, M. (2010). A benefitsbased study of Appalachian Trail users: Validation and application of the benefits of hiking scale. Physical Health Education Nexus, 2(1), 1-22.

Füller, J., \& Matzler, K. (2008). Customer delight and market segmentation: An application of the three-factor theory of customer satisfaction on life style groups. Tourism Management, 29 (1), 116-126.

Fullerton, G., \& Taylor, S. (2002). Mediating, interactive, and non-linear effects in service quality and satisfaction with services research. Canadian Journal of Administrative Sciences / Revue Canadienne des Sciences de L'Administration, 19(2), 124-136.

Gyimóthy, S., \& Mykletun, R. J. (2004). Play in adventure tourism: The case of Arctic trekking. Annals of Tourism Research, 31(4), 855-878.

Honey, M. (2008). Ecotourism and sustainable development: Who owns paradise? Washington, DC: Island Press.

Hyun, M. Y., Park, Y. A., \& Kim, Y. G. (2016). Motivations to walk Jeju "Ollegil", South Korea: Development and validation of a walking motivation scale. Tourism Planning \& Development, 13(4), 486-503.

Jaccard, J., Brinberg, D., \& Ackerman, L. J. (1986). Assessing attribute importance: A comparison of six methods. Journal of Consumer Research, 12(4), 463-468.

Jeju Tourism Association. (2017). Jeju tourism statistics. Retrieved from http://www.visitjeju.or.kr/web/bbs/bbsDtl.do?pagelnde $\mathrm{x}=1 \& \mathrm{sBbsld}=$ TOURSTAT\&bbsld $=$ TOURSTAT\&noticeNum $=249$ \&authNum $=\&$ sKeyOpt $=1 \&$ sKey $=$

Kang, G. K. (2014). A research on creating Samnamgil Trail. Advanced Science and Technology Letters, 52, 125-130.

Kano, N., Seraku, N., Takahashi, F., \& Tsuji, S. (1984). Which service quality dimensions are important in inbound tourism. Managing Service Quality, 16(5), 520-537.

Kastenholz, E., \& Rodrigues, Á. (2007). Discussing the potential benefits of hiking tourism in Portugal. Anatolia, 18(1), 5-21.

Keniger, L. E., Gaston, K. J., Irvine, K. N., \& Fuller, R. A. (2013). What are the benefits of interacting with nature? International Journal of Environmental Research and Public Health, 10(3), 913-935.

Kim, S., Choe, J., \& Petrick, J. (2018). The effect of celebrity on brand awareness, perceived quality, brand image, brand loyalty, and destination attachment to a literary festival. Journal of Destination Marketing \& Management, 9 (September), 320-329.

Kim, B., Kim, S., \& Heo, C. (2016). Analysis of satisfiers and dissatisfiers in online hotel reviews on social media. International Journal of Contemporary Hospitality Management, 28(9), 1915-1936.

Kim, B., Kim, S., \& Heo, C. (2019). Consequences of customer dissatisfaction in upscale and budget hotels: Focusing on dissatisfied customers' attitude toward a hotel. International Journal of Hospitality and Tourism Administration, 20(1), 15-46.

Kim, B., Kim, S., \& King, B. (2016). The sacred and the profane: Identifying pilgrim traveler value orientations using meansend theory. Tourism Management, 56, 142-155.

Kim, H., Lee, S., Uysal, M., Kim, J., \& Ahn, K. (2015). Nature-based tourism: Motivation and subjective well-being. Journal of Travel \& Tourism Marketing, 32(Suppl. 1), S76-S96.

Kim, S., Schuckert, M., Im, H., \& Elliot, S. (2017). An interregional extension of destination brand equity research: From China to Europe. Journal of Vacation Marketing, 23(4), 277-294.

Kozak, M. (2001). Repeaters' behavior at two distinct destinations. Annals of Tourism Research, 28(3), 784-807.

Lau, A. L., \& McKercher, B. (2004). Exploration versus acquisition: A comparison of first-time and repeat visitors. Journal of Travel Research, 42(3), 279-285.

Lee, W. S., Kim, J., Graefe, A. R., \& Chi, S. H. (2013). Valuation of an eco-friendly hiking trail using the contingent valuation method: An application of psychological ownership theory. Scandinavian Journal of Hospitality and Tourism, 13(1), 55-69.

Li, P., Bin, Z., \& Ryan, C. (2017). Hiking in China: A fuzzy model of satisfaction. Tourism Management Perspectives, 22, 90-97.

Li, X. R., Cheng, C. K., Kim, H., \& Petrick, J. F. (2008). A systematic comparison of first-time and repeat visitors via a two-phase online survey. Tourism Management, 29(2), 278-293.

Ma, J., Gao, J., Scott, N., \& Ding, P. (2013). Customer delight from theme park experiences: The antecedents of delight based on cognitive appraisal theory. Annals of Tourism Research, 42, 359-381.

Maas, J., Verheij, R. A., Groenewegen, P. P., De Vries, S., \& Spreeuwenberg, P. (2006). Green space, urbanity, and health: How strong is the relation? Journal of Epidemiology \& Community Health, 60(7), 587-592.

Magnini, V. P., Crotts, J. C., \& Zehrer, A. (2011). Understanding customer delight: An application of travel blog analysis. Journal of Travel Research, 50(5), 535-545.

Marafa, L. M., Ting, H. Y., \& Cheong, C. K. (2007). Perceived benefits of hiking as an outdoor recreation activity in Hong Kong. Licere, Belo Horizonte, 10(2), 1-26.

Marcus, C. C., \& Barnes, M. (Eds.). (1999). Healing gardens: Therapeutic benefits and design recommendations. New York: John Wiley \& Sons.

Maria Raya, J., Martínez-Garcia, E., \& Celma, D. (2017). Economic and social yield of investing in hiking tourism: The case of Berguedà, Spain. Journal of Travel \& Tourism Marketing, 35 (2), 148-161.

Matzler, K., Hinterhuber, H. H., Bailom, F., \& Sauerwein, E. (1996). How to delight your customers. Journal of Product \& Brand Management, 5(2), 6-18.

Matzler, K., \& Sauerwein, E. (2002). The factor structure of customer satisfaction: An empirical test of the importance grid and the penalty-reward-contrast analysis. International Journal of Service Industry Management, 13(4), 314-332.

Mikulić, J., Dužević, I., \& Baković, T. (2015). Exploring drivers of student satisfaction and dissatisfaction: An assessment of impact-asymmetry and impact-range. Total Quality Management \& Business Excellence, 26(11/12), 1213-1225.

Mikulić, J., \& Prebežac, D. (2008). Prioritizing improvement of service attributes using impact range-performance analysis and impact-asymmetry analysis. Managing Service Quality: An International Journal, 18(6), 559-576. 
Mikulić, J., \& Prebežac, D. (2012). Using dummy regression to explore asymmetric effects in tourist satisfaction: A cautionary note. Tourism Management, 33(3), 713-716.

Mittal, V., \& Kamakura, W. A. (2001). Satisfaction, repurchase intent, and repurchase behavior: Investigating the moderating effect of customer characteristics. Journal of Marketing Research, 38(1), 131-142.

Moore, R. L., \& Ross, D. T. (1998). Trails and recreational greenways: Corridors of benefits. Parks \& Recreation, 33(1), 69-79.

Moore, R. L., \& Shafer, C. S. (2001). Introduction to special issue trails and greenways: Opportunities for planners, managers, and scholars. Journal of Park and Recreation Administration, 19(3), 1-16.

Mu, Y., \& Nepal, S. (2016). High mountain adventure tourism: Trekkers' perceptions of risk and death in Mt. Everest Region. Nepal. Asia Pacific Journal of Tourism Research, 21(5), 500-511.

Nordbø, l., \& Prebensen, N. K. (2015). Hiking as mental and physical experience. In Advances in hospitality and leisure (pp. 169186). Emerald Group. https://www.emeraldinsight.com/doi/ book/10.1108/S1745-3542201511

Nunnally, J. C. (1978). Psychometric theory (2nd ed.). New York: McGraw-Hill.

Oliver, R. L., Rust, R. T., \& Varki, S. (1997). Customer delight: Foundations, findings, and managerial insight. Journal of Retailing, 73(3), 311-336.

Oppermann, M. (1997). First-time and repeat visitors to New Zealand. Tourism Management, 18(3), 177-181.

Oppermann, M. (1998). Destination threshold potential and the law of repeat visitation. Journal of Travel Research, 37(2), 131-137.

Petrick, J. F. (2004). Are loyal visitors desired visitors? Tourism Management, 25(4), 463-470.

Plutchik, R. (1980). Emotion: A psychoevolutionary synthesis. New York: Harper \& Row.

Prince, S., \& loannides, D. (2017). Contextualizing the complexities of managing alternative tourism at the communitylevel: A case study of a Nordic eco-village. Tourism Management, 60, 348-356.

Rust, R. T., \& Oliver, R. L. (2000). Should we delight the customer? Journal of the Academy of Marketing Science, 28(1), 86-94.
Sarigöllü, E., \& Huang, R. (2005). Benefits segmentation of visitors to Latin America. Journal of Travel Research, 43(3), 277293.

Shanka, T., \& Taylor, R. (2004). Discriminating factors of first-time and repeat visitors to wine festivals. Current Issues in Tourism, 7 (2), 134-145.

Statista. (2017). The statistics portal. Retrieved from https://www. statista.com/statistics/191240/participants-in-hiking-in-theus-since-2006/

Su, L., Swanson, S. R., \& Chen, X. (2018). Reputation, subjective well-being, and environmental responsibility: The role of satisfaction and identification. Journal of Sustainable Tourism. doi:10.1080/09669582.2018.1443115

Torres, E. N., \& Kline, S. (2006). From satisfaction to delight: A model for the hotel industry. International Journal of Contemporary Hospitality Management, 18(4), 290-301.

Um, S., Chon, K., \& Ro, Y. H. (2006). Antecedents of revisit intention. Annals of Tourism Research, 33(4), 1141-1158.

Weaver, D. (2001). Ecotourism as mass tourism: Contradiction or reality? The Cornell Hotel and Restaurant Administration Quarterly, 42(2), 104-112.

Weaver, D. B., \& Lawton, L. J. (2007). Twenty years on: The state of contemporary ecotourism research. Tourism Management, 28 (5), 1168-1179.

Wolf, I. D., Brown, G., \& Wohlfart, T. (2017). Applying public participation GIS (PPGIS) to inform and manage visitor conflict along multi-use trails. Journal of Sustainable Tourism, 26(3), 470-495.

Wolf, I. D., \& Wohlfart, T. (2014). Walking, hiking and running in parks: A multidisciplinary assessment of health and wellbeing benefits. Landscape and Urban Planning, 130(1), 89-103.

Woo, K. S., Sohn, Y. K., San Ahn, U., Yoon, S. H., \& Spate, A. (2013). Jeju Island Geopark-A volcanic wonder of Korea. Berlin Heidelberg: Springer.

Woodham, O. P., Williams, J. A., \& McNeil, K. R. (2016). Toward understanding the impact of attributes on satisfaction in different price tiers. Journal of Consumer Satisfaction, Dissatisfaction and Complaining Behavior, 29, 91-117.

Ye, B. H., Fu, H., \& Law, R. (2016). Use of impact-range performance and asymmetry analyses to improve OTA website quality. Journal of Hospitality and Tourism Management, 26, 9-17. 